\title{
RILEM BULLETIN BULLETIN DE LA RILEM
}

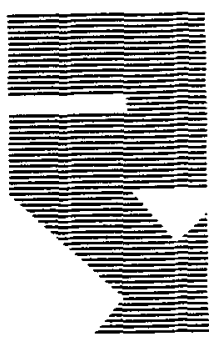

\section{OBITUARY}

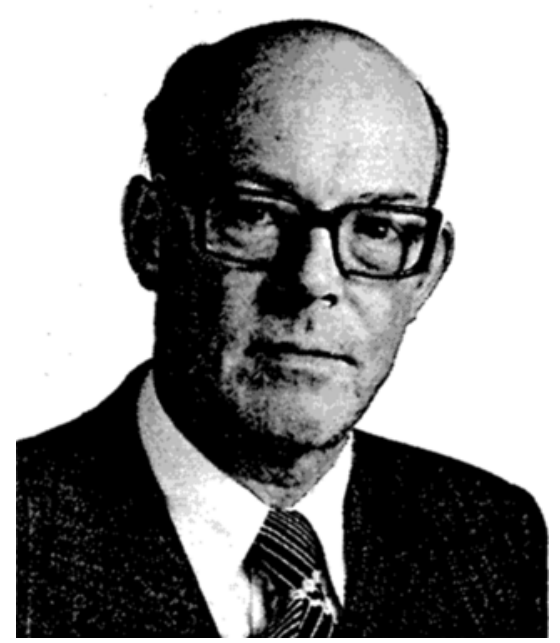

Sven Gabriel Bergström

Professor Sven Gabriel Bergström died on 24 June 1990 at the age of 70 years. Bergström was very active in RILEM for a long period, contributing in various capacities in the organization as such, as well as in the technical work as Technical Committee chairman and symposia organizer. Bergström always considered RILEM to be the most important com- ponent in his international network, underlining the importance of the professional technical discussions held within the RILEM scientific community, as well as the genuine friendship he enjoyed with many RILEM members. He was RILEM Delegate in Sweden from 1969 to 1983.

Bergström graduated in civil engineering at the Royal Institute of Technology in Stockholm in 1942. He presented his doctoral thesis in 1951, and shortly afterwards he joined the Swedish Cement and Concrete Research Institute (CBI) as a researcher in the technical and physical departments. In 1953 he was appointed head of the consultancy department, and later he became responsible also for the education department. In 1964 Bergström was installed as professor in the Department of Building Materials at Lund Institute of Technology. Eight years later he returned to CBI, now as Director, and remained in that position until he retired in 1934.

Professor Bergström had numerous Swedish as well as Nordic and other internationai assignments. He was a member of many committees for standards and codes and, in the beginning of the seventies, Bergström was chairman of an important study group examining the organization of Swedish concrete research. He was active in the Nordic Concrete Federation as chairman, and was responsible for the establishment of the journal Nordisk Betong. He also participated as chairman in various joint research programs in the Nordic countries. Bergström received several Swedish as well as international awards.

Although Bergström had a heavy burden following his various administrative and organizational commitments, he was all the time very close to research matters. He was deeply involved in the planning and discussion of research projects, and through his leadership many researchers have attained academic degrees. Characteristic of Bergström was his ability to link a fundamental approach in research with requirements in practice. Bergström's research environment was also to a great degree characterized by attention to fundamental mechanisms and close involvement with users.

Sven Gabriel Bergström was a great personality. His knowledge, his skilful analysis, his positive attitude and his laughter will long be remembered. It might be seen as a sign that he died during midsummer - days in the Nordic countries connected with light and hope. 